\title{
The Early Days of Chemical Ionization: A Reminiscence
}

\author{
F. H. Field \\ Oak Ridgt. Tenne'sse'e, LSA
}

\begin{abstract}
A narrative account is given of the events leading to the discovery of chemical ionization in the laboratorics of the Humble Oil and Refining Company in 1965. The discovery was unplanned in the sense that it resulted from the observation of unanticipated phenumera made in the collrse of experiments undertaken for a differenl purpose. However, the sequence of eventi which occurred is an illustration of the discovery of a practical, useful result from a program of research which was primarily of a basic nature but with ancillary awareness of possible practical implications. (f Am Soc Mass Spectrom 1990, 1, 277-28.3)
\end{abstract}

$\mathrm{T}$ This is a retrospective article suggested by Fditror Mike Gross in which 1 shall attempt to give an account of the discovery of chemical ionization mass spectrometry (CIMS). I initially had some concern about the existence of a retrospective sendency in ASMS, for a preoccupation with history is oftentimes an indication that an institution or organization or discipline has matured and perhaps is even entering a decline. However, three milliseconds of reflection brought me to the realization that in the past year or two mass spectrometry has seen the development of methods which produce mass spectra of proteins in the 100,000-300,000 u range (matrix assisted laser desorption and electruspray ionication), and this on top of the ten to fifteen years of marvels associated with massive particle bombardment desorption mass spectrometry. Advances in other subdivisions of the discipline might also be sited. It is abvious that any discipline with that degree of vitality can look back to its history with relative impurity. I digress to say that I have been associaled with mass spectrometry now for over forty years, and in that time its history has been one of progress from one exciting peak of interest and discovery to the next. In my opinion the present period is at least as exciting as any that has existed until now.

Mass spectrometry started in the early part of the twentieth century, but even by the end of Wirld War $\amalg$ it was being pursued in only a small number of laboratories. This was especially true of the organic mass spectrometry to which I shall restrict my subsequent remarks. While mass spectrometers were available commercially at the end of the war, they were prohibitively expensive, for a Consolidated Engineering Corp. Model 101 instrument cost about $\$ 35,000$. Federal funding for scientific researth was five to ten

Address peprint requests lo Frank It. Fjetd, 1.3 Mwore Lane, Oak Ridge, Th 37830 . years in the future, and to provide a scale of reference, my annual cesearch grant as an instructor and assistant professor at the University of Texas was $\$ 200$. One could in principle construct an instrument for less than $\$ 35,000$. but the technigues involved were arcane and not widely known. Petroleum and chemical cumpanies were the ony organizations which had both the money and the need for mass spectrometry, and consequently the discipline was dominated by industrial mass spectrometrists, and the contribution that they made to the field was very great. One should also mention the importart compilation of mass spectra started by the National Burcau of Standards in about 1947.

The industrial contributjuns were usually empirical and practical, directed primarily to the development and use of analytical procedures, but fortunately some of the major companies were both affluent enough and enlightened erough to support some basic resterch. The Humble $\mathcal{O}^{i}$ and Refining $\mathrm{Co}$. (part of what is now Exxon (orporation) in Baytuwn, Texas, was une of these companics, and in 1951 a small basic research program in mass spectrometry was started under the very ablc direction of Joe Franklin. 1 joined the research program shortly after its inception. The rationale for the work was that organic ions, particularly carbocations, are very much involved in a number of very important petrolcum refining processes, and Joe Franklin believed that information ubtained in the gas phase about the intrinsic properties of these ions would contribute to an understanding of their behavior in practical condensed phase processes.

Our initial research activities involved measuring ionization and appearance potentials using the electron jonization (EL) vanishing current method. While by present standards this method was crude and inaccurate, in fact the measurements (by uthers as well as by curselves) were tremendously important, for they gave some of the first quantitative information abut the energies of gasenus organic ions. However, we and 
everyone else working in the field of chemical physics mass spectrometry (all 15-25 of us) were tremendously exciled by the 1952 paper by the Soviet mass spectronetrist Viktor Talrose and his associate A. K. Lyubimova [1] stating that $\mathrm{CH}_{5}$ exisled and was produced by running methane in a mass spectrometer at an elevated pressure (perhaps about $10^{-2}$ torr). (I might add parenthetically thal at this time it was believed by almost all mass spectrometrists that the sky would fall if one tried to operate a mass spectrometer at any pressure higher than about $10^{-6}$ torr.) Joe Franklin and I resolved to make some high-pressure experiments as soon as prior abligations permitted. W'e made a few preliminary experiments with our Westinghuuse Type LV mass spectromeler (a $90^{\circ}$ sector instrument, design resolution about 100), and we found that, indeed, we could raise the pressure in the ion source to about 10 microns (the torr unit of pressure was just beginning to come into use) without catastrophe. Consequently, at our first opportunity to get back to full-time experimental work we started a program of work in the brand new, thrilling field of ion-molecule reactions wherein startling, unexpected reactions occurred without activation energies at rates appruaching $10^{-4} \mathrm{~cm}^{3}$ i\{mol.s\}.

Our efforts in making measurements of ion energies were successtul enough that Joe Franklin and 1 were persuaded that we could profitably use a mass spectrometer designed for and dedicated to studies in chemical physics mass spectrometry. We made a proposal to this effect to the company (Humble Oil and Refining ( $(0)$ ), and moncy was first appropriated for design expenses and then for construction. The amount involved was more than $\$ 100,000$, which would be somewhere between $\$ 500,000$ and $\$ 1,000,000$ in today's dollars. And all of this on the strength of a five-page written proposal and an explanatory conversation with the boms of the laboratory-the goud uld days!

By the time the design of the new instrument was completed, we had already made a number of studies of ion-molecult reactions using other mass spectrometers in the laboratory, and we had gained cnough experience to suspect that providing a high pumping speed on the machine would be desirable. The commercial mass spectrometers of the period were equipped with the most modest of pumping capacities. Mass spectrometers were for the very largest part used only for El analytical measurements, and consequently the pressures involved were very low $\left(10^{6}-10^{5}\right.$ torr). The gas loads were thus also very luw, and the manufacturers were doubtless delighted to save some money by providing only a very limited pumping capacity-only a few tens of liters per second. as best I recall. This was the tolal pumping on the mass spectrometer tube, and no differential pumping on the analyzer portion of the tube was provided. Because of this the early ion-molecule studies were made with the instruments operating close to their upper pressurc limits giving broad ion peaks because of scattering and retrograde sensitivity; that is, intensity decreased as the pressure was increased. Thus in the design of the new mass spectmometer, which by now we were proudly calling the llumble Chemical Physics Mass Spectrometer, we incorporated the highest pumping capacity of which we could conceive-250-L's pumps on both the ion suurce envelope and the analyzer tube with only the final slit of the source ion optical system serving as the opening between the source region and the analyzer region. The pumps were connected to the mass spectrometer tube by 4 -in.-diameter tubes, and the diameters of the source and analyzer envelopes were correspondingly large. Because of this the machine was looked upon by all who heard about it or eventually saw it as something of an extravagant monstrosity. Of course, the designer did not join in this opinion because of paternal pride. A picture of the machine in its very early days (about 1960) is shown in Figure 1. The picture gives a good view of the high capacity pumping system. It is clear from the size of the instrument that compactness was not a design goal, The operatur in the picture is Wilburn Gieger, whose help with the construction and operation of the ma. chine in Baytown contributed greatly to its success.

The machine came on stream (to use the parlance of the refinery in which it was located) in March 1959. and after some initjal shakedown and familiarization runs a study of the ion-molecule reactions in thylene was started. About three years previously we had done a study uf ethylene using a small machine [2], finding some interesting results, and we were cager to restudy the system with the new machine, which we did. The study was very successfal and yielded many interesting new results. Pressures up to 350 microns ( 0.35 torr) were used, and I was enough carried away by this accomplishment that I used the adjective "ultra-high" in referring to these pressures in the title of the paper I wrote describing the work [3]. Among other things we observed the occurrence of multiple-order reactions (as high as sixth order) to produce the $\mathrm{C}_{7} \mathrm{H}_{13}^{+}$ion from ethylene. We were able to deduce that the rate constants for ternary reactions were of the order of $10^{27}$ $\mathrm{cm}^{3} /(\mathrm{mol} \cdot \mathrm{s})$ and the rate constants for the decompositions of intermediate complexes were on the order of $10^{7} \mathrm{~s}^{1}$. It was clear that opening up this high-pressure regime significantly extended the range and types of ion-moleculc reactions which could be studied.

In spite of thjs promise, it was several years before the really high pressure capabilities of the machine were used in our studies. And the reason is that we were seduced by a fascinating diversion. It is truc that a study of ion-molecule reactions in methane up to an ionization chamber pressure of 0.35 torr was made [4], and a similar study was made with ethane, propane. and butane [5], but for a period of several years our main research effort was in the direction of the djversion. Shortly after the ethylene study we had discovered (stumbled on is perhaps not as inappropriate characterization) some vory unexpected ionic reactions 


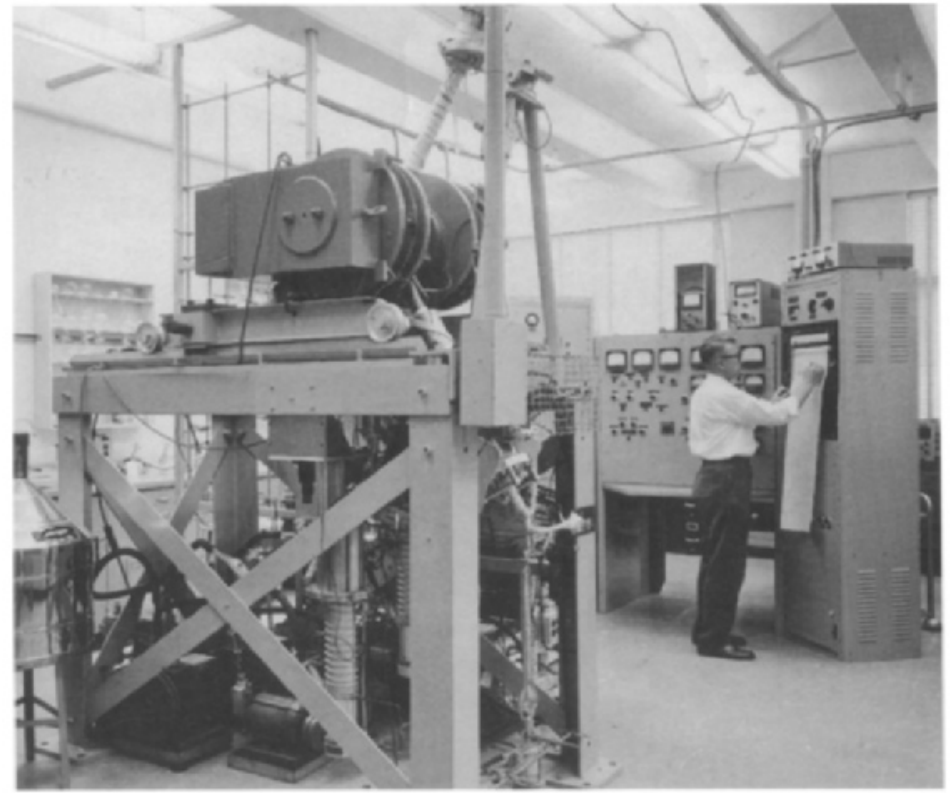

Figure 1. Humble Chemical Physics Masa Spectrometer, Humble Oil and Refining Cn., Baylown, Texas, ca. 1960 . The operator is Wilburn Gieger. Reprinted with permission from loumal of the American Chemical Society, 1965, 87, 3291. (c) 1965 American Chemical Suciety. involving rare gas ions. For examplc, we discovered the existence of $\mathrm{Xe}_{3}\left(\mathrm{CH}_{4}\right)^{\prime}$ [6]. This even antedated the first discovery by Nieil Bartlett in 1962 of the production of stable compounds involving rare gas atoms, so our discovery was of much interest. As an aside, I presented a paper on the $\mathrm{Xe}\left(\mathrm{Cl}_{4}\right)^{\prime}$ work al the Second International Conference on Mass Spectrometry in Oxford in 1961, and the chairman of the session was so captivated by the material that he forgot the time, and I inadvertently spoke for five minutes more than 1 had been allotted.

We published several interesting papers on this general subject, but by the end of 1964 a grawing worry began to assail me, and this worry had to do with relevance. Relevance is a term (other words to express the same concept duubtless exist) which is of importance in almost any scientific laboratory which is part of or is supported by a goal-uriented organization. Because of some corporatc rcalignments the laboratory in which I worked was now supported by Esso (now Exxon), and Essn's goal was to find petroleum, grocess it, and sell the products. By several different means it was made known that the research wurk to be done in the corporation should be relevant to that goal. Up to that time we working in chemical physics mass spectrometry had had just about absolute freediom to do what we wanted, and we were given generous suppurt. The work we were doing with rare gas ions was good research, but it had a very academic flavor, and I thought the probability low that it would have much impact on the refining of petroleum. No real pressure was brought to bear on us by the cumpany cuncerning the relevance matter, but I thought that the relevancy request by the company was reasonable, and I supported it. It seemed to me that the best way of being relevant while doing basic scientific work was to revert back to using our fine machine to study ionic reactions in hydrocarbons. We thought that studying such reactions at increasingly high pressures might give us information about ionic reactions in hydrocarbons in condensed phase, which would certainly be both relevant and of real scientific interest. A secondary consideration caused us to work further with methane. A concern among some hydrocarbon chemists at the time was that there ought to be something better to do with the vast amounts of methane then available (the supply looked inexhaustible in the early 1960s) than just burn it as natural gas. We wondered if perhaps these marvelous new ion-molecule reactions might serve to convert lowly methane into something more useful and profitable. So we decided to switch our main research effort to a really high pressure study of the inn-mulecule reactions in methane.

It is probably desirable at this time to define who were the "we" that I refer to repeatedly in this paper. The initial workers in the group were Joe Franklin and myself. Fred Lampe joined us in about 1954, and he left in 1960 to take a position at Penn State. Jean Futrell was in effect part of the group, although his main assignment was radiation chemistry. He was in residence in the period 1958-1959, after which he left to meet a military service obligation. All of these dates are from memory, and some may be in error by a year or so. Burnaby Munson joined the group in about 1960 to take Fred Lampe's place. Joc Franklin left in 1964 to become the first Robert A. Welch Professor at Rice Unjversity. So in the pertod which 1 am now discussing, which is the period immediately prior to the discovery of chemical ionization, the two remoining workers in the group were Burnaby and myself.

As I mentioncd above, in previous studies we had achieved uperation of the mass spectrometer at pres- 
sures up to about 0.35 torr, and we now modified the instrument to attempt to operate at pressures higher than this. This involved decreasing the size of the electron entrance and ion exit slits in the ionization chamber of the machine and making sure that the chamber was as gas tight as possible otherwise. The new dimensions of the two slits were $0.05 \times 3 \mathrm{~mm}$ and $0.05 \times 5 \mathrm{~mm}$, respectively. The electron current entering the ionization chamber was only $0.05 \mu \mathrm{A}$, which was partly the consequence of the small electron entrance slit, but also partly because the olectron emission current was only about $6 \mu \mathrm{A}$. This low current was primarily the consequence of the practice in those days of using low emission currents to prolong the life of the filament. This was not really unwarranted, since in many machines a half day or more was required to change a filament. Our situation was exacerbated by the fact that we were using iridium for the filament for fear that the high pressure we were striving for would cause rapid deterioration of a tungsten or thenium filament. The electron emissivity of iridium is quite low.

The first important discovery that we made, although we really didn't appreciate it, was that the ions found in methane at high pressure depended strongly on the presence of even quite small amounts of impurities. Water is a universal impurity in mass spectrometry, and ethane is found in small amounts in even the best grade commercial methane. Our goal was to get the high-pressure spectrum of pure methane, so the best available grade of commercial methane was subjected to a rigorous purification procedure. Methane was condensed in liquid nitrogen, and a center cut of this was then distilled onlo Linde $5 \mathrm{~A}$ molecular sieve maintained at liquid nitrogen temperature. The material sorbed on the sicve was distilled off and again a center cut was collected and stored in a glass vessel. The apparatus, including the sicve, was evacuated for $12 \mathrm{~h}$ prior to use, and immediately before the purification it was heated to $350^{\circ} \mathrm{C}$ while being evacuated. The temperature of the glass storage vessel was alsu raised during evacuation to reduce sorption of impurities on the walls. Material sorbed on the iлterior surfaces of the mass spectrometer and the gas inlet lines also caused difficulties, and rcally satisfactory measurements were oblained only after the mass spectrometer had been in continuuus use in $\mathrm{CH}_{4}$ ser vice for several weeks.

With these precautions some beautiful spectra of mothane were obtained at pressures up to 2 torr. Figure 2 shows the relative concentrations of the important ions from methane as a function of ionization chamber pressure, and Figure 3 shows the relative concentration of $\mathrm{C}_{2} \mathrm{~J} \mathrm{l}_{3}^{\prime}$ as a function of ionization chamber pressure including individual experimental points taken mer a period of 2 months. The high degree uf reproducibility was very gratifying. Both Figures 2 and 3 are taken from ref. 7 . The lack of variation of the relative intensities of $\mathrm{CH}_{n}^{+}$and $\mathrm{C}_{2} \mathrm{H}_{3}^{\prime}$ above abuut 0.1 torr shows that these ions do mut react with methane and thus will have a long lifetime in methane. We

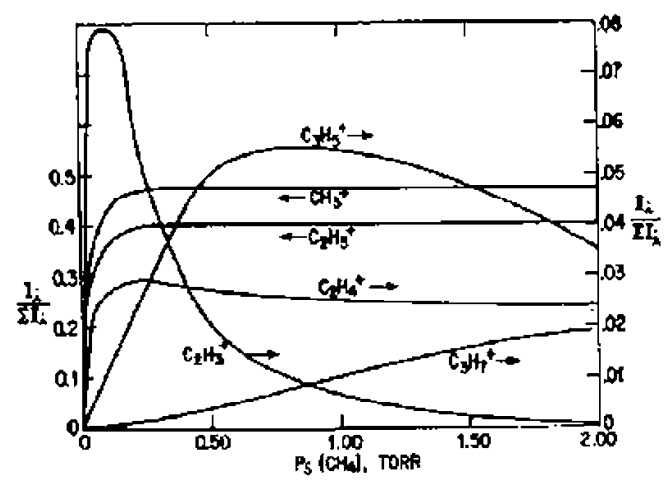

Figure 2. Relative intensibics of ions from $\mathrm{CH}_{\text {s }}$ as a function of $\mathrm{CH}_{4}$ pressuce. Reprinted with permission from joumtal of the Amenion Chemial Sinioty, 3965, 87, 3291. (c) 196.5 American Shemical Socrety.

thought that this was the most important conclusion to be drawn from the experiment, but in the paper we wrote describing the research [7] we stated just in passing that we estimated the water content of the methane to be about $0.01 \%$, but at a pressure of 2 torr the $\mathrm{H}_{3} \mathrm{O}^{+}$ ion comprised about $1.5 \%$ of the total ionization of the system, and to quote directly, "thus providing an illustration of the high probability of proton attachment to water and the relatively large number of collisions the ions make in the innization chamber at high pressure." In retrospect this clearly was a manifestation of CI, although of course we did not recognize it as such at the time.

However, it was clear that interesting reactions with small amounts of impuritics were occurring and that an investigation directed specifically at the effects of various impurities on the high-pressure methane speetrum was in order. Since we were in a petroleum company we wert strongly interested in hydricarbons, so the additives to methene that we first investigated were ethane and propane (8). The technique used in those days was to make up a mixture of methane with a small amount of the additive (we used $1 \%$ ) and measure the spectra of the mixture as a function of the pressure of the mixture in the ionization chamber of the mass spectrometer. Under these conditions the rel-

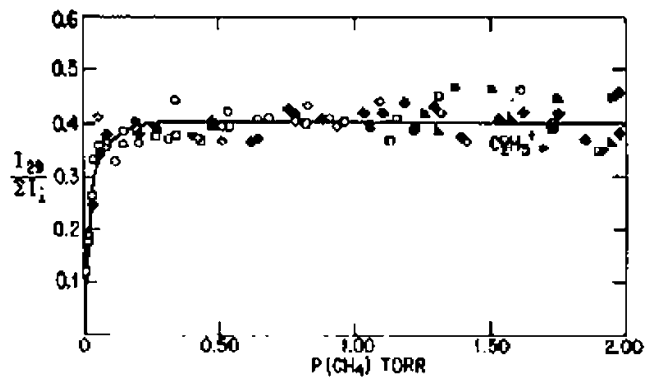

Figure 3. Relative intersity of $\mathrm{C}_{2} \mathrm{H}_{5}^{+}$as a function of $\mathrm{CH}_{4}$ source pressure showing experimental points. These were laken over a period of several months. Reprinted with permission from fournal of the American Chemical Society, 1965, 87, 3297. (C) 1965 American Chemical Society. 


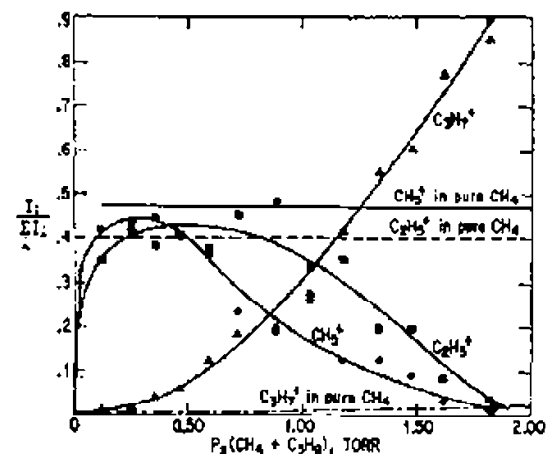

Figure 4. Intensitues of ions from the mixturs $\mathrm{CH}_{4}+1 \% \mathrm{C}_{3} \mathrm{H}_{4}$ as a function of pressure. From tel. 8 .

alive intensities of ions formed by ion-molecule reactions increased with increasing pressure, and the relative intensities of ions consumed by jon molecule reactions decreased. Figure 4 shows a plot of the relative concentrations of $\mathrm{CH}_{5}^{+}, \mathrm{C}_{2} \mathrm{H}_{5}^{+}$, and $\mathrm{C}_{3} \mathrm{H}_{7}^{+}$as a function of the preasure of a mixture of methare with $1 \%$ propane. Clearly, both $\mathrm{CI}_{5}^{+}$and $\mathrm{C}_{2} \mathrm{H}_{5}^{+}$react with propane to produce $\mathrm{C}_{3} \mathrm{H}_{7}^{+}$, which comes to dominate the spectrum at high pressures. In tact it is for all practical purposes the only ion produced from propane by these ion-molecule reactions, and the very large difference between this spectrum and that produced in propone by EI certainly did not escape our attention and interest. The intensity of the molecule-ion in the El spectrum of propane is not particularly small, but it does not comprise the major fraction of the total ionization, and this difference between the El spectrum and that which we produced by ion-molecule reactions with ions from methane was really most interesting-

We then moved on to $n$-butane as an additive and found the same general results as with propane; that is, as the pressure of the mixture of butane and methane was increased the intensity of the butyl jon $\left(\mathrm{C}_{4} \mathrm{H}_{4}^{+}, m / 257\right)$ steadily increased and became virtually the sole inn in the spectrum.

This work was not published as such, but we really wero beginning to get exsited. It had been known from the National Bureau of Standards compilation of spectra (1947) that the relative intensity of the mulecule-ion in the El spectra of normal paraffin hydrocarbons undergoes a monotonic decrease as the number of carbon atoms in the molccule increases, disappcaring at about $C_{36}$. By the time one gets to $C_{6}$ (n-hexane), the molecule-ion intensity is quite small-only a few percent of the base peak and. of course, less of the total ionization. Thus we decided to make what we considered to be a crucial experiment, namely, mcasuring the spectra of a mixture of $n$-hexane in methane as a function of pressure. I can still remember the interest (and trepidation) with which we monitored the $\mathrm{C}_{6} \mathrm{H}_{13}^{+}$ion intensity as the pressure of the mixture in the mass spectrometer was increased. At the conclusion of the experiment we observed with great excitement that. unce again, the alky! ion produced by removing a hydride ion from the parent molecule dominated, and a really new and potentially important phenomenon was at hand. Indeed, we then even tried a highly branched paraffin which gave no molecular ion by EI (2,2-dimethylbutane), and we found to our delight that the methane ionication spectrum contained an appreciable amount of quasi-molecular ion $\left([\mathrm{M}-1]^{+}\right)$.

The excitement we felt had two aspects. The theoretical one was that the extensive molecule-ion decomposition observed under El with the straight-chain paraffin hydrocarbons (which were just about the only relatively large, linear moleculos then amenable to mass spectrometric investigation) was not occurring with the type of ionization occurring in our systems. We immediately recognized that the ions produced by the abstraction of a hydride ion from the paraffin hydrocarbon were even-electron ions rather than the odd-electron ions produced initially by $\mathrm{EI}$, and the stabilities and decumposition paths of the two might well be different, with more stability to be found in the former. We also thought it quite likely that the amount of energy transferred to the quasi-molecular ions in the ion-mulecule reactions was smaller than in the cortesponding EI casc. That is to say, the ionization was softer, although I don't think that this term had as yet been invented, and it certainly had not been applied to mass spectrometry. We recognized the importance and were very cxcited by the apparent existence of a new type of gaseous ionization and one with properties diflerent from those of EI. At the time photoionization had been used in some basic mass spectrometric studies, and field ionization was about to be discovered, but for practical purposes EI was the overwhelmingly domiluant type of ionization available to organic mass spectrometrists. While it had obvious strengths, it also had some weaknesses that had to be accepted because uf the lack of a practical alternative.

The second aspect of our excitement was a practical one. Mass spectrometers in a petroleum company laboratory were analytical instruments, and while the basic research that we were doing was an exception to this generalization, we were always aware of the analytical activities and problems in which our distinguished analytical colleagues at Baytown (Earl Lumpkin and Tom Acrel) were involved, and we were eager for our basic studies to contribute to the greatest extent possibte to the solution of these problems. About ten years carlier we had made a basic research contribution to analytical problems in the form of low voltage ionization mass spectrometry. This technique has since been developed by Earl Lumpkin and especially by Tom Aczel, and is still in extensive use, but that is another story. In any event, the spectra formed in n-paraffins by reactjons with the jons from methane seemed to offer a way of solving an important problem in hydrocarbon chemistry. namely, finding a quick method for obtaining the carbon number distribution in a mixture of saturated hydrocarbons. We had succeeded in doing this for unsaturated and aromatic 
compounds with our low voltage El method, but as I mentioned above, under El the molecule-jon intensities in $n$-paraffins rapislly decrease as the size of the molecules increases. Furthcrmore, for branched paraffins the situation is worse: the decrease in molecule-ion intensities is more rapid, and for very highly branched paraffins it is zero even for small compounds, for example, neopentane. Because of their cyclic structure, naphthenes exhibit more intense molecule-ions but even with these compounds the intensities get weak as the molecules get quite large. In addition, there are quite a number of other types of compounds-amines. for example-which produce small or zero moleculeions; in fact J have seen an estimate (in McLafferty's monograph?) that about $20 \%$ of organic compounds do not produce molerule-ions by EI. We wondered if perhaps our new method of ionization would provide a higher percentage of stable molecule-ions (actually quasi-molecular jons). However, L should point out that not many mass spectrometrists were interested in or even aware that a problem concerning moleculeion stability existed. Perhaps the main thrust of basic organic mass spectrometry at the time was attempting to understand the decomposition reactions occurring under EI, and so what if some compounds had completely unstable molecule-ions? Deducing the structure of compounds from their mass spectra was a popular activity (to call it a game would be a bit pejorative), and iragmentation was generally looked upon as highly desirable. Our position as petroleun chemists gave us a different point of view. I might say that twenty-five more years in the real analytical world using various kinds of ionization techniques including $\mathrm{Cl}$ leaves me still convinced of the importance of finding a moleculeion or ions in the spectra of real analytical samples, particularly for new compounds or those for which no authentic spectrum is availabie.

In order further to investigate our interesting now iusnizatiun method a quicker and more cunvenient way of introducing the sample was needed. It was obvious that instead of making a nixture of sample and methane outside the mass spectrometer and introducing the mixture into the spectrometer, it would be easier to have separate introductions of each component (with the methane flowing continuously) so that the mixture would be made inside the spectrometer. Fortunately, in the original design of the mass spectrometer two separate sample introduction systems had been provided to deal with a possible need such as that which we now had. Thus the separate introduction of the methane and the sample could be accomplished quite easily, and we set out to make a survey of the spectra produced by different types of compounds. We also recogiuzed at this early time that compounds other than methane could be used as the reactant; in particular we knew that i-butane and propane would be less energetic in producing product ions and that hydrogen would be more encrgetic. We further recognized that one could mimic EI spectra by using sub-

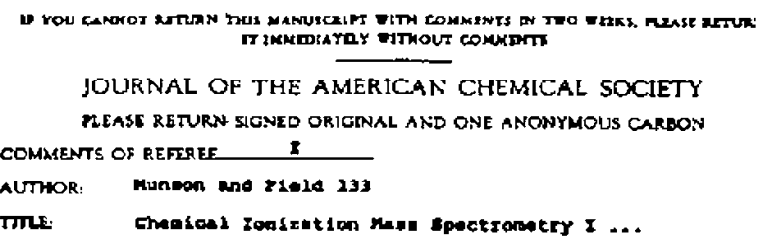

COMWENTS:

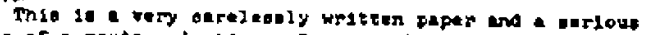
weste of a reviever's tibe. In general, the ereanctaint

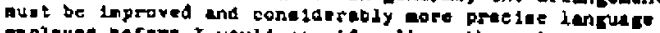
employed berore $I$ whid consider $1:$ por un putilohting.

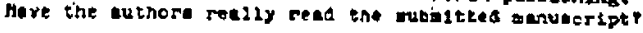

Page 7. 2no paragraph - Th1s caragraph do utcorly ridicujous in both contens oud eonstrutian. The ent1re paragreph onojld be ar.jtted. If the cuthore Inalot on lneliding the ralt to ben:enea. Flemat make it "eli inm-covered prozelain trit."

\$. 2, 2. 20. The authors migt be joking: what dota ino

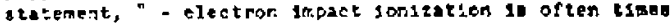
atliofactory" meani $k 200$ lne reference to tho ue of $H_{2}$ needs futther explanelion.

Fp 13, et ea. I ear net urgue uges the a.jthor's conjectures

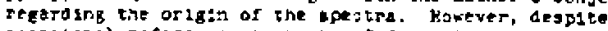
ocezsiorol referericts to restas of somation end exotherale reactisrs, conjecture is all it is. When ome oboervetions (e.8. D. 31) art "expladnez by the use of inpure meteriade

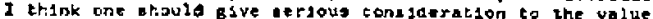
of the wark ana tine userulines of publication.

Figure 5. Revintier's comments un the manuscript first introducing chemical jonization. In spite of the review, the manuscript was published [9].

stances such as nitrogen and nitric oxide which would produce odd-electron ions as reactants. We guessed that analogous negative jon reactions would occur. A small number of experiments to establish the validity of these expectations were made.

The results of cour survey of different compounds using methane was excitingly successful, for we found strong quasi-molecule-ions and cven some uscful, understandable fragmentations. We prepared a manuscript describing our work and submitted it to JACS as an article. We were so convinced of the importance of the work that in addition we sent copies of the manuscript to about 50 mass spectrometrist friends. which is something I had never done before nor have done since. In writing the paper it became clear that a short, descriptive, snappy name for our new ionization techrique was needed, and since the product ions of interest were formed by chemical reactions, we hit on the name "chemical ionization," which in retrospect was a felicitous choice. We worried that a confusion with the term "chemi-ionization" (as in the production of $\mathrm{CHO}^{+}$from excited $\mathrm{O}$ and $\mathrm{CII}$ might occur, but the only objection or problem of which I ever heard was from Viktor Talrose, and I assume that this had more to do with the translation into Russian than with the English tcrm.

The JACS reviewer who dealt with the paper was very negatively impressed with our efforts, and I give as Figure 5 a reproduction of his extraordinar- 
ily derogatory review. The manuscript was in fact well written, and I can orly conclude that the newness of the material exceeded the scope of the reviewer's imagination and comprehension. This matter now seems to be only amusing, but at the time our feelings were a good deal stronger. We made a few cusmetic changes in the manuscript, shortening it a bit in noncritical places (always a desirable tactic with negative reviews), and we resubmitted it with a stiffish letter to the Editor giving our views of the validity of the reviewer's comments. We prevailed, and the paper was published [9].

I need not do more here than to state that following this rather contentious introduction the CI method has grown to have widespread use. About two years ago I did a search using the CA Online facility and found that as of that time approximately 1500 articles had been written wherein the term "chemical ionization" was used in the title or the abstract. The only sad aspect of the whole matter is that I lumble (Esso, Exxon) as far as I know has not profited from this work as much as one would have liked. At Humble we were successful in getting a strung patent on the CI method, but Esso saw fil to sell the rights for the patent for a really trivial amount of money, and the purchaser realized the not inconsiderable royalties (by scientific instrument marufacturing standards) that the patent generated. Furthermore, our hopes that the method would be particularly useful in the petroleum industry for the delermination of carbon number distributions in saturates seems not to have been realized. However, from our point of vjew as discoverers of the techrique, its success in larger contexts than hydrocarbon chemistry, that is, in organic chemistry in general and in biochemistry, has been tremendously gratifying to me and, I am sure, to Burnaby.

\section{References}

1. Talrose, V. I., Lyubimova, A. K. Dokl, Akad. Nauk S\$SR 1952, 86,909

2. Field, F. H.; FoankJin, I. L.; Lampe, F. W. I. Apm. Chem. Soc. $1957,79,2419$.

3. Field, F, H. 1. Am. Chem. Sor., 1961, 83, 1523

f. Field, F, H.; Franklin. J. L.; Munson, M. S. B. I. Am. Chem. Sic. 1963, 35. 3575 .

5. Munson, M. S. B.; Tranklin, J. L.; Hield, F. H. /. Phys. Chtm. 1964. 68, 3098 .

6. Field, F. H,; Ftanklin, J. L. J. Am. Chem. 5oi. 1961, 83, 4509.

7. Field, F. 11.: Munson, M. S. R. 1. Am. Ctem. Soc. 1965, 87, 3289.

8. Munson, M. S. B., Field, F. H. J. Am. Chem. Sor. 1965, 97, 3294.

9. Musison, M. S. B., Field, F. H. 1. Am. Chem. Sox. 1966, 88, 2621 . 